operation too great care cannot be taken in purifying the hands, instruments, dressings, \&c. The instruments necessary are an ordinary bistoury, two or three osteotomes (Fig. 1) or chisels of different sizes, a mallet, and a small firm sand-bag enclosed in a carbolised towel
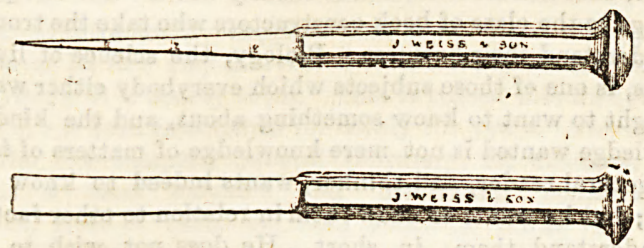

Fig. 1.-Ostrotome.

The limb is flexed, and laid on its ouler side firmly sup. ported by the sand-bag. A longitudinal incision, about one inch in length, slightly in front of and above the adductor tubercle on the inner aspect of the internal condyle, is made right down to the bone. No normal ressel of importance is cut. The osteotome is passed into the wound, turned so as to lie at right angles to the long axis of the femur, and then by short sharp strokes

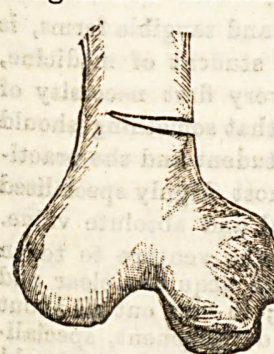
of the mallet is driven through four-fifths of the thickness of the bone, care being taken to avoid the posterior aspect lest the popliteal vesseis be injured. A carbolised swab of wool is placed over the wound, and under cover of it the chisel is withdrawn. The surgeon now forcibly breaks through the rest of the thickness of the femur, and places the limb in a good position. It is found advisable to FIG. 2.-Diagram showing over-correct the displacement, as line of bone section in otherwise during the process of MacEwen's operation of repair a slight degree of deformity is sometimes reproduced.

Two or three catgut stitches are used to close the wound in the soft tissues and facilitate primary union, a dry antiseptic dressing is applied, and the limb immobilised by being encased in plaster of Parisfrom the toes up to the groin, a small window being left to facilitate the examination and, if necessary, the dressing of the wound. The original plaster case is replaced at the end of four or six weeks by a lighter appliance, such as starch or poroplastic, and the patient goes about on crutches till the bones are sufficiently consolidated to sustain his weight.

\section{BRISTOL GENERAL HOSPITAL.}

\section{Treatment of Tuberculous Glands.}

Mr. Penny in the early stage lays great stress on the improvement of general hygiene conditions - fresh air, - tonics, preparations of iron in the form either of the componnd syrup of the phosphate of iron or the syrup of iodide of iron, cod liver oil, and port wine. He also uses the ointment of iodide cadimum or oleate of mercury, and iodine applications. When the glands have begun to soften and suppurate, he opens the softening mass and scrapes out the caseous material freely, until firm tissue is reached, and then applies to the cavity a solution of chloride of zinc of the strength of forty grains to the ounce of water. If the abscess has already opened he slits up the undermined skin, and scrapes round under it, and trims off any overhanging bits. Small holes in the facia are to be carefully looked for. They often lead into further suppurating cavities beneath, and when practicable must be carefully laid open, and the caseous matter beneath as carefally scraped away as in the more superfical collections. Volkman's spoon is the best instrument, to remove the caseous tubercular tissue with. If there should be free oozing a piece of "protective" is placed next the wound and into cavity, and the part plugged. The "protective" will enable it all to slip away the next day without disturbing the clots. The dressing consists of boracic lint, or boracic or iodoform ointment, and if there is much discharge, a lajer of wood wool wadding.

\section{GLAMORGANSHIRE AND MONMOUTHSHIRE INFIRMARY, CARDIFF.}

Treatment of acute Pneumonia.

The treatment of acute pneumonia forms one of the most instructive chapters in the history of medicine, and illustrates in a striking way the vicissitudes and fortunes of the healing art during the last half-century. When the present consulting physicians, fresh from the influence of the Paris school, joined the staff of the Cardiff Infirmary, bleeding was in full force, and resorted to almost in every case as a matter of routine, in much the same way as poultices are used at the present day. Der ressing drugs, such as antimony, in the form of tartar emetic and James' powder, assisted, in the views of that time, to "crush out" the disease. The inevitable reaction came, and the restorative treatment, with its large quantities of brandy, had its day. Since then various drugs have appeared on the scene, each claiming to shcrten the course or lessen the mortality of the disease. Among them quinine, digitalis, aconite, veratria, and the alkalis were the most pro. minent, but even these have been abandoned by their friends, except in combating special symptoms. All this violent swinging of the pendulum has not been without its value, for it has taught the broad principles upon which a disease, like pneumonia, naturally tending to cure, should be treated. Belief in "systems" is now dead, and it is recognised that the only rational treatment is to carefally consider the value of the various symptoms as they arise, the extent to which they affect the patient's comfort and recovery, and accordingly require treatment or not. Many circumstances bave to be carefully weighed, and above all it is important to remember that the patient, rather than the disease, is the primary object of treatment.

Of the local applications used at the Cardiff Infirmary in the treatment of acute pneumonia, perhaps the majority of cases have on admission linseed-meal poultices. These are applied to the affected side and renewed every three hours. This affords early relief to the pleuritic pain frequently so prominent, and of late years have been entirely limited to this end. A feeling that continuous hot poulticing is very exhausting to the patient, without much corresponding benefit, has led to the adoption of a simple cotton wool jacket, which retains the heat sufficiently, and, moreover, aroids the necessity of disturbing the patient. It may be that the suceess of cold applications to the chest, introduced of recent years, has drawn attention to this point, as it is certainly the case that routine poulticing is experiencing the fate of other "systems," and falling rapidly into disuse. For severe pain hot fomentations, with or without a few drops of turpentine, are used, as counter-irritation can be more rapidly carried out. Blisters are, as a rule, avoided, on account of the discomfort and inconvenience of a tender, raw surface. When there is much distress with the pains leeching is resorted to, three to six being placed over the spot where pain is located; if necessary, hot fomentations are applied subsequently to encourage bleeding.

To relieve the cough and promote expectoration, such remedies as the expectorant medicines, ipecacuanha wine, compound tincture of camphor, and squills in the form of tincture, syrup, or hymel are given. In sthenic cases, antimonial wine has been long a farourite for the same purpose, serving, as it does, further to moderate 
the rapidity of the circulation and stimulate the skin. In children, the bronchitis kettle with a tent bed is occasionally used, but, like poulticing, not to the extent it was formerly.

For the promotion of sleep, one of the chief points in the treatment, the different hypnotic remedies are in use. When pain is present, its relief is important. When the insomnia is not due to pain, small doses of the bromides and chloral hydrate, or in form of bromidia, are given frequently; and of the newer drags, sulphonal and chloralamide have proved valuable. A combination of tincture of digitalis and chloral hydrate, in the pro. portion of seven drops of the former to five grains of the latter, given every four hours-as recommended by Dr. Balfour, of Edinburgh-is sometimes employed, and found to act well in cases advanced in life, where there is much restlessness with weak heart action. Alcohol, in the form of brandy, is also used as a hypnotic, half an ounce to one ounce being given at bed-time.

In severe dyspnœa, with a tendency to cyanosis, venæsection has been resorted to on a few occasions within the last ten years, with relief certainly, though of a temporary character. Each time not more than ten or twelve ounces of blood were withdrawn. Recently the employment of oxygen inhalations has been tried, the apparatus being that supplied by the Brins Oxygen Company. Much good result has not so far been obtained, but the treatment has not been sufficiently tried to determine with accuracy the limits of its uses.

To control pyrexia, quinine has always been a favourite drug, in doses varying from five to twenty grains, as often as the circumstances require. Aconite is used by others, who believe it of great value for this purpose, in drop doses of the tincture every quarter of an hour for the first hour, and then every hour afterwards until the temperature falls. Salicylate of soda is likewise employed, but more rarely on account of its tendency to produce unpleasant symptoms. Of the newer anti-pyretics, antipyrin in doses of ten grains every two or three hours, and antifebrin in smaller quantities are as yet used sparingly. On the whole, it is only in a few that antipyretic drugs have been found of any value. Cold, in the form of baths, cold effusions to the chest, and the cold pack, have not been tried. Recently, however, at the Union Hospital Dr. Sheen has used the ice-bag in over twenty cases of pneumonia, all of which recovered. It was found to give much relief to the symptoms, and in a few there was reason to think that the spread of the disease was arrested and its duration shortened. On several occasions, it was striking to observe how a patient, semi-delirious with severe pain, became calmed and fell asleep after the ice-bag had been on the affected side half an hour. It always had a favourable influence on the temperature, and the further advantage that the effect could be readily controlled. This, of course, places it, as an antipyretic agent, above the usual drugs, the notorious uncertainty of which has been the sub iect of much scoffing at the hands of cynics, from Voltaire downwards. The ice-bag is the most convenient form of applying cold, and if care be taken to have a tightfitting cap which does not leak, the patient may be kept perfectly dry and comfortable. It is kept on the chest until the temperature falls below 101 deg., and reapplied on any rebound.

Delirium, when it is marked, is generally treated by stimulants, brandy being the form used. In Dr. Sheen's cases the ice-bag had a very decided effect in relieving this symptom. In alcoholic patients with delirium the bromides with chloral are mostly relied npon.

Where the acute stage is past, and the lung resolving but slowly, counter-irritation by iodine or small fly blisters is had recourse to, while iodide of potash and cinchona mixture is administered internally, and, later on, tonics containing iron, quinine, strychnine, \&c.

\section{THE PRACTITIONERS' BOOKSHELF.}

\section{THE BEGINNINGS OF LIFE.*}

It is a great advantage to the beginner in biology to have a text-book written by a medical man-always supposing, of course, that the medical man can really writs. Dr. Campbell belongs to the class of book constructors who take the trouble to understand their business. Biology, the science of living things, is one of those subjects which everybody either wants or ought to want to know something about, and the kind of knowledge wanted is not mere knowledge of matters of fact. The general reader, and thinker, wants indeed to know the facts ; but he wants to know them in relation to other factsto understand them, in short. He does not wish to see things out of proportion, to take a biological mouse for an elephant, or vice versa. Moreover, he likes to see the facts in a historical setting. He does not wish to announce to his friend, in conversntion, \& fact as a new discovery which is two or three centuries old. But all these mistakes are constantly being made by even intelligent people who come new to the subject. Medical students themselves, to say nothing of practitioners, are frequent blunderers in this regard, and in them such blundering is inexcusable.

Life, as it manifests itself in visible and tangible forms, is the great business of the scientist, the student of medicine, and the medical practitioner. The very first necessity of successful work among living forms is that something should be known about them. The medical student and the practitioner deal with living forms of the most highly specialised variety, of the greatest physiological and absolute value. The first thing, then, that all people who venture to touch the subject of medicine should do is to acquire a clear and intelligent knowledge of living forms ; to find out all about their various modes of life, nutrition, development, specialisation, and death. Every medical student, indeed, should become a biologist at the beginning of his career, and every medical practitioner should continue to be an intelligetn biologist throughout his life.

But if this be what is naturally demanded of medical men, it is essential that biology shall be reduced to its simplest elements, and shall be so presented by teachers to students that there shall be no unnecessary difficulty in understanding it. This task of making biological science simple, easy of comprehension, and interesting is what Dr. Campbell has set himself; and he has succeeded excellently well. The book, however, though simple, is thoroughly scientific ; and is only popular in the sense that Dr. Campbell has put himself in the place of the reader, and has done what every teacher is morally bound to do-made "the crooked straight and the rough places plain." But it is not by medical students alone that such a book as this should be read and studied; it is the very book for the high school and the college. One would think that the clergy, too, who, as public teachers, ought to be familiar with the scientific lines on which men's thoughts are more and more running every day, would be glad of a book of the kind. It is small - containing less than 300 quarto pages - and cannot be very expensive. Moreover, it is thoroughly trustworthy and up to date ; the work of a competent teacher and honest scien. tific worker. We regret that, from want of space, our notice is necessarily of a cursory character; but the merits of the little book are great, and the service it can render to intelligent readers will be found to be also great.

\section{THE HYGIENE OF THE EAR. $†$}

Dr. Cozzolino's little work has already run through four editions, and has been translated into six European languages, surely good evidence that it has proved of value to the medical profession and the public. The hygiene of the ear in infancy, childhood, adult life is dealt with in a plain and impressive manner, and the concluding chapter on general contains many valuable suggestions.

* “Elementary Biology.” Bg H. J. OAMP BeLL, M.D. Lund, Demon. strator of Biology and Physiology at Gay's Hospital. (London, Swan Sonnenschein and Oo.; New York, Macmillan and Oo.)

†"The Hygiene of tha Fir." By Dr. Vincenzo OozzoninO (Naplei). Translated from the Fifth Italian Edition by James Ensirine, M.A.. M.B., Glaggow. Pp.52 870, Bailliére, Tindall, and Cox, London, 1892 . 